\title{
Risk aversion, path dependency and financial economic decision-making in low-income communities: Experimental evidence from South Africa
}

\begin{tabular}{|c|c|}
\hline \multicolumn{2}{|c|}{ 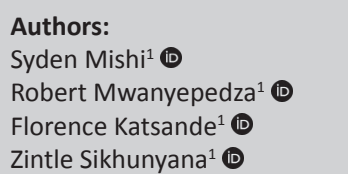 } \\
\hline \multicolumn{2}{|c|}{$\begin{array}{l}\text { Affiliations: } \\
{ }^{1} \text { Department of Economics, } \\
\text { Faculty of Business and } \\
\text { Economic Sciences, Nelson } \\
\text { Mandela University, Port } \\
\text { Elizabeth, South Africa }\end{array}$} \\
\hline \multicolumn{2}{|c|}{$\begin{array}{l}\text { Research Project Registration: } \\
\text { Project Number: MS001 }\end{array}$} \\
\hline \multicolumn{2}{|c|}{$\begin{array}{l}\text { Corresponding author: } \\
\text { Syden Mishi, } \\
\text { Syden.mishi@mandela.ac.za }\end{array}$} \\
\hline \multicolumn{2}{|c|}{$\begin{array}{l}\text { Dates: } \\
\text { Received: } 01 \text { Mar. } 2020 \\
\text { Accepted: } 02 \text { Oct. } 2020 \\
\text { Published: } 08 \text { Dec. } 2020\end{array}$} \\
\hline \multicolumn{2}{|c|}{$\begin{array}{l}\text { How to cite this article: } \\
\text { Mishi, S., Mwanyepedza, R., } \\
\text { Katsande, F. \& Sikhunyana, Z., } \\
2020, \text { 'Risk aversion, path } \\
\text { dependency and financial } \\
\text { economic decision-making in } \\
\text { low-income communities: } \\
\text { Experimental evidence from } \\
\text { South Africa', Journal of } \\
\text { Economic and Financial } \\
\text { Sciences 13(1), a562. https:// } \\
\text { doi.org/10.4102/jef.v13i1.562 }\end{array}$} \\
\hline \multicolumn{2}{|c|}{$\begin{array}{l}\text { Copyright: } \\
\text { (C) 2020. The Authors. } \\
\text { Licensee: AOSIS. This n } \\
\text { is licensed under the } \\
\text { Creative Commons } \\
\text { Attribution License. }\end{array}$} \\
\hline \multicolumn{2}{|l|}{ Read online: } \\
\hline 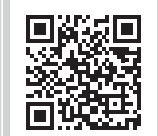 & $\begin{array}{l}\text { Scan this } Q R \\
\text { code with your } \\
\text { smart phone or } \\
\text { mobile device } \\
\text { to read online. }\end{array}$ \\
\hline
\end{tabular}

Orientation: Poverty is deeply entrenched in South Africa, and various initiatives to reduce it have not been successful. Behavioural economics may help explain this by testing whether individuals exhibit path dependence when making decisions under uncertainty.

Research purpose: The aim of this article was to test the presence of path dependence and the determinants of risk aversion.

Motivation for the study: This study was conducted in Eastern Cape province of South Africa, which is largely rural, with a high level of poverty, where $36 \%$ of households depend on social security grants, and unemployment is higher than the national average.

Research approach/design and method: An experimental design approach was applied, eliciting risk under different prospects. Descriptive statistics was used to determine path dependency, with random effects regression used to investigate the determinants of risk aversion.

Main findings: The results show the existence of path dependence, with individuals who are more risk averse unwilling to change their choices even if they stand to win or lose more than in the previous period.

Practical/managerial implications: Policymakers need to consider these behavioural characteristics in formulating policies to reduce poverty. Information and how that information is presented (framing) are central for impactful policy formulation.

Contribution/value-add: The results here have policy implications on addressing triple challenges bedeviling South Africa and many developing countries.

Keywords: decision-making; experimental economics; inequality of opportunities; livelihoods; poverty; uncertainty.

\section{Introduction and background of study}

Poverty is one of the triple challenges bedevilling South Africa post-apartheid, alongside inequality and unemployment. Government has come up with numerous strategies to address these challenges, but with little success (Mosala, Venter \& Bain 2017). In finding a lasting solution, the literature points to understanding individuals' decision-making, especially in the face of information asymmetry (World Bank 2015). Welfare economics makes a general assumption that individuals are risk neutral and are completely rational; this is often done to simplify policy formulation as literature has shown heterogeneity and non-rationality (Harrison 2019; Harrison, Lau \& Rustrom 2007). Alternative theories have emerged, positing that individuals are not rational with many explanations around bounded rationality, such as limited capacity and time, information asymmetry and poverty (Banerjee \& Mullainathan 2010) amongst other reasons. Even though poverty may impair decision-making (Mani et al. 2013), some of the apparently irrational behaviours observed amongst the poor may have a rational explanation. This article seeks to investigate one such possible explanation, that is, path dependence (Yesuf \& Bluffstone 2009).

Recent literature asserts that risk preferences differ amongst individuals based on many factors, and the degree of risk aversion can help understand differences in well-being (Banerjee \& Ewing 2004; Concina 2014; Harrison 2019; Thomas 2016; World Bank 2015). In addition, there are many information processing errors and biases that affect decision-making by individuals and households, more severe in failed markets. Information asymmetry leads to market failure which 
increases transaction costs and impacts negatively, disproportionately so for the low-income individuals and households. Sources of low-income households are generally undiversified, therefore implying great risk of loss (Achiba 2018; Concina 2014). Where multiple income sources are present, they are often of low value (requiring more human resources, as low-income households often rely on quantity of labour than on quality). The households therefore face risk of member illness, death and/or divorce (Mabilo 2018), which become extreme shocks to income. It is also imperative to note that market imperfections are prominent in lowincome societies and consumption and production decisions are not separable (Binswanger 1981).

Addressing poverty and the inability of households to shift risks to third parties because of market failure, where one cannot find suitable insurance or it is non-existent, extremely limited access to credit, and experiencing thin or non-existent labour markets require an in-depth understating of decisionmaking process. The said constraints on households and individuals restrict their ability to prepare for and react to shocks, leaving them vulnerable. Because of fear of the unknown, lest more is at risk, the poor sometimes remain poor because they are not willing to alter their choices, thereby displaying path dependence (Yesuf \& Bluffstone 2009). The socio-economic conditions of decision-makers can indeed play an important role in shaping their preferences, beliefs and behaviour, as well as constraining their action set. This justifies the need to investigate decision-making process as part of finding solutions for individuals of similar observable characteristics (such as poverty). It is imperative to note that the observable characteristic like poverty, unemployment may be the same, but the circumstances leading to that circumstance and its entrenchment may be very different. In the same token and of interest to this article is that decisions taken in the context of poverty may by themselves dynamically contribute to shaping the economic prospects of decision-makers.

Path dependence has been discussed in economics, policy studies and organisational decision-making (Arthur 1983; Dobusch \& Schübler 2013; Sydow, Schreyögg \& Koch 2009; Webster 2008). The argument is that 'history matters', that is, the current state mirrors the recent past, in the context of a 'lock-in phenomena' (David 1985). In the context of poverty, the assertion is taken to mean that path dependence is a condition in which economic outcomes exhibit inertia - they are what they are (poor) because they have been what they have been (poor). This study seeks to investigate if this holds in practice, and therefore can help to explain economic outcomes of individuals and households. As South Africa grapples to address the triple challenges, the solution could be within individuals' behaviour as espoused in Simatele et al.'s (2016) framework. ${ }^{1}$ The framework posits that poverty

1 Viewed 13 March 2019, from http://psppdknowledgerepository.org/component/ jdownloads/send/23-grantee-research/609-enhancing-pro-lowincome-growththrough-livelihood-strategies-in-the-eastern-cape-province?option=com jownloads. can be alleviated by focusing on mind-set/mentality (M), affording access to assets (A) and having prioritisation order $(\mathrm{P})$, with a clear strategy (S), which is popularised through the acronym MAPS.

Policy-makers, interest groups and academicians alike have tried to understand the triple challenges and attempted to find a solution, but without much success. Weaknesses in current policies and development programmes are to assume that individuals are rational and risk neutral and the risk preference is homogenous across society. The World Bank (2015) report entitled 'Mind, Society and Behaviour' points to new approaches of investigating socioeconomic problems within society. Indeed, classical theory with rationality assumption fails to explain why the low income may remain in such a state in the face of multitudes of developmental initiatives. General economic and financial decision-making are of interest to unpack factors driving economic coordination within society for better economic surplus. Theory should go beyond how decisions should be made, and how are they being made and why such decisions are made.

Risk-averting behaviour triggered by such set of constraints sets is of interest as it could lead to risk-induced path dependence and poverty traps. Even if risk preferences are fundamentally the same, those who can prepare for and insure their consumption against shocks take advantage of profitable but risky opportunities, whilst others could be limited to low-risk, low-return activities and lives of poverty. Any household with sufficient ex-post coping mechanisms may accept risks, including those associated with useful policy interventions to improve rural livelihoods, whilst riskneutral households with limited insurance could avoid risky investments. Strategies to eradicate or alleviate poverty reduce inequality and/or create employment need to take this into consideration: impact of wealth, other ex-post coping mechanisms, key covariates on risk-averting (departure from risk neutrality and homogeneity assumption by traditional welfare economists).

It is now over 20 years since the end of apartheid spatial system in South Africa in 1994, which promoted exploitation and marginalisation of the black population majority; however, poverty levels continue to escalate, and the rate of unemployment continues to rise despite all government efforts (David et al. 2018). Eather and Frawley (2015) further asserted that poverty levels in South Africa are traced to the continued rise in formal unemployment, unequal distribution of income, wealth and unavailability of business opportunities - a clear existence of inequality of opportunities. In order to earn a living, South Africans have resorted to survival entrepreneurship (Ndabeni, Maharajh \& Economy 2013) and other multitude of subsistence-economic activities. The increase in number of households is retrenched in the formal sector, not able to find jobs and those who do not have adequate educational qualifications to get formal jobs are driving the growth of the informal sector in 
South Africa (Eather \& Frawley 2015). These 'unemployed' citizens are penetrating different sectors in the informal sector, which include manufacturing, agriculture, mining, finance, transport, community and social services and trade (Ndabeni et al. 2013).

Experiences and transitioning trajectories differ markedly across population groups and gender. Mabilo (2018) has shown that female-headed households dominate the informal sector, majorly in response to shocks such as divorce and death of spouse. According to Sharyn, Roshan and Duncan (2018), other women work in the informal sector to support their husbands as their income will not be sustaining the family. Compounding the fact that households in the informal sector face challenges of obtaining jobs in the formal sector, they do not have higher educational qualifications or any vocational course, most of them left school before they completed their studies and if completed they failed in high school level (Rogan \& Skinner 2017). These household characteristics tend to influence reward obtained in the informal sector and this justifies the relationship between poverty and informal sector in South Africa. Participating in the informal sector comes with high risk as compared to the formal one with all guarantees and security (Tsurui-Sato et al. 2018). The South African national, provincial and municipal governments have not yet taken any radical policy to embrace informal trading activities despite the role and contributions towards employment and poverty eradication (Sharyn et al. 2018). Pillay (2008) believes that the failure of authorities to address informal trading issues in South Africa is traced to colonialism and apartheid trajectory. In addition, this may depict the view of informal sector in South Africa as parasitic (bad for the economy in general) and not from a positive point such as a reservoir of entrepreneurial talent (the training ground for entrepreneurs) or the dualistic view where the formal and informal complement each other and are not competitors.

This study seeks to answer the following research questions that are highly interrelated and critically important for policy formation:

- How does the build-up of wealth at very low-income levels affect risk behaviour?

- In low-income settings, how does the possibility of loss affect aversion to risk?

- Do past successes within risky environments affect subsequent risk responses?

- Do levels of potential gains and losses affect responses to risk?

To answer these questions, this empirical work takes on an approach with two components:

- An experiment that seeks to understand households' responses to risk (risk preferences) using real monetary pay-offs (to avoid bias) (List \& Shogren 1998). Prospects within the experiments mimic risky household investment decisions framed around common economic activities like street vending, jobbing to measure risk aversion. There are two versions of experimental frameworks: Gains only (Appendix 1) versus Gains \& Losses (Appendix 2) tasks. Each of the framework has five rounds (first three rewards real money (real), and the last two are hypothetical); each round consists of five prospects (ordered 5, 4, 3, 2,1) from which a subject must choose only one prospect. A subject, therefore, makes five choices (one per round) under each version of task (see Appendix 1 for illustration of the tasks).

- Outcome of risk aversion measurement is then used as a dependent variable in random effects model that adjusts for a variety of covariates to explain the risk behaviour in terms of household and game (experimental task) structure.

This is a behavioural economics approach, with motivations concerning apparent weaknesses in standard economic theory: people sometimes make choices that are difficult to explain using standard economic theory, and standard economic theory can lead to seemingly unreasonable conclusions about consumer welfare (Harrison et al. 2007; Mullainathan et al. 2013). On the other hand, behavioural economics grew out of research in psychology, anthropology, biology and neural sciences. The objective is to modify, supplement and enrich economic theory by adding insights from these disciplines. Suggesting that people care about things, standard theory typically ignores elements like fairness or status, allowing for the possibility of mistakes (O’Donoghue 2015; Wilkinson \& Klaes 2012; World Bank 2015). This is never to replace or refute completely the traditional economic theory; rather it is about catering for its weaknesses and providing better insights for policy formulation and monitoring.

The organisation of the article is as follows: the next section presents the literature reviewed, providing both theoretical and empirical literature. Then the methodology is discussed, followed by the Results section. Finally, the 'Conclusion' section concludes the article and provides recommendations.

\section{Literature}

Theories relevant to this study are expected utility theory (Bernoulli 1713) and prospect theory (Kahneman \& Tversky 1982). People make decisions / choices daily without knowing much about the outcomes of such decisions - an inherent uncertainty characterising decision-making environment. Knight (1921) stated that uncertainty is an imperative potency which provides knowledge and understanding about how an economy operates. Such a phenomenon is explained by expected utility theory, through an account of how to choose rationally when you are not sure which outcome will result from your acts. The theory has multiple applications; for example, it can be taken as normative theory, in that it explains how people should make decisions. We need to understand how those living in poverty-stricken communities make decision given multiple deprivations they face. On the 
other hand, the theory can be taken from classical point of view as descriptive in nature demonstrating how people make decisions. From how individuals should make decision to how do they make decision, critical information for policymaking can be deduced, especially in the fight of poverty, unemployment and inequality, which requires certain behavioural traits. In addition, the expected utility theory can still be considered a predictive theory, and even though it may not accurately model the psychological mechanisms of decision-making, it, however, correctly predicts people's choices.

Expected utility theory was first introduced by Daniel Bernoulli with the motive of solving St. Petersburg paradox (1713) of believing in infinite expected values in a game of chance. Bernoulli's utility function provided a mathematical solution to a theological and philosophical perspective and argued that rational individuals make decisions on the basis of marginal utility and not on the expected value of money (Golik 2016). Because of the law of diminishing marginal utility, marginal utility of money decreases as value for money increases. Bernoulli solved the Petersburg paradox (1713) by concluding that as marginal utility of money decreases, individuals will stop betting, thus avoiding the principle of infinity (Golik 2016).

The theory is, however, heavily criticised by Kahneman and Tversky $(1979,1982)$ based on growing body of evidence inconsistent with the assumptions made. Growing empirical literature has suggested that standard expected utility maximisation is either not an appropriate behavioural model or has refined the conditions under which apparent behavioural anomalies like loss or small stakes risk aversion are consistent with expected utility theory. Prospect theory, proposed in 1979 by two psychologists - Daniel Kahneman and Amos Tversky - is considered an alternative to expected utility theory and a better explanation of decision-making by individuals. Expected utility theory evaluates an outcome based on total resources and multiplies each valuation by its probability. Prospect theory, on the other hand, evaluates an outcome based on the change in total resources and judges alternatives according to the gains and losses they generate relative to the status quo.

Prospect theory explains how people make decisions based on potential chances of having losses and gains given their current relative positions. Since individuals make decisions based on heuristic approach, there is a greater emotional bearing connected to potential losses than gains. As individuals are assumed to dislike losses to gains, the theory implies that people are risk averse. Fear of depleting current position as an unintended consequence of seeking more gains, that is, being concerned with losing what one already has more than obtaining some gain, individuals become loss averters to maintain their state (Tversky \& Kahneman 1992). This is in line with the design of this study in which we compare prospects where gains only are expected and where gains and losses are possible and determine the decision- making in those contexts. Individuals weigh gains and losses differently, and there can be general aversion to losses even if small in the face of high gains. In this study, the decision for those qualifying to enter a second lag of the experiments (gains and losses) after accumulating above minimum threshold earnings (R150, approximately \$10) from the first lag (gains only) is observed as an extreme form of risk version (mainly in the form of loss aversion). The prospects are designed in such a way that risk increases gradually and choices in successive prospects can depict whether one changes decision-making pattern depending on earnings accumulation (Rosen-Schwarz \& Shapira 2018). This is in line with what Langlois and Cosgel (1993) observed that risk taking and uncertainty influence the levels of profitability in a business. Transitioning out of poverty therefore depends on decisionmaking under uncertainty and risk preferences.

Empirical literature is building up on the relationship between risk aversion, path dependency and poverty. Developing and emerging economies have been characterised by poverty hitting hard on most of their people. Initiatives by many organisations, government and regional blocks have focused more on eradicating poverty in these countries. Despite the efforts, certain groups of people have remained poor. The investigations why most people remain poor besides the world over establishing policies and initiatives to eradicate poverty have given rise to adopt a behavioural economics approach to ascertain the matter. Sarlo (2013) defined poverty as the inability to meet basic needs, which results in unavailability of community decency causing exposure to public shame. According to Statistics South Africa (2018), the upper-bound poverty line (UBPL) is at R1183, Food poverty line (FPL) at R547 and lower-bound poverty line (LBPL) is R785 per month.

Binswanger (1980) investigated how attitude towards risk influenced decision-making in low-income countries, which is in line with the interest of this study. Considering farmers in India, the experiment used hypothetical and real pay-off of lotteries where outcome probabilities were constant, but the pay-off of the lotteries differed. Binswanger (1980, 1981) concluded that most farmers were risk averse. Furthermore, it was concluded that choices of farmers in India were consistent with a decrease in absolute risk aversion, whilst relative risk aversion increases. A similar study was conducted in Indonesia and Zambia by Miyata (2003) and Wik et al. (2004), respectively, which proved Binswanger's $(1980,1981)$ results, stating that villagers in Indonesia and Zambia face a decrease in absolute risk aversion whilst relative risk aversion increases. According to Meyer and Meyer (2005), relative risk aversion can be defined as a tool that is used to measure risk preferences that are determined by a description of outcome variable and the way the outcome variable is used as utility function argument. One of the research questions is to examine the effects of gains and loss on risk, and relative risk aversion will also be considered as a variant to the measuring of risk aversion. With relative risk aversion, we observe a subject shying away from risky prospects as he or she accumulates more wealth (increase in 
earnings accumulation). A subject also displays extreme relative risk aversion when he or she accumulates more from the gains only and refuses to 'gamble' with the earnings in the gains and losses part of the experiment.

Mosley and Verschoor (2005) conducted a similar study in the case of Ethiopia, India and Uganda. Considering joint choices with putative equivalent questions, Mosley and Verschoor (2005) found that there is no substantial relationship between risk aversion and socio-economic indicators such as income, wealth, literacy, gender and age. However, risk aversion is correlated to pay-off of lotteries if real pay-offs of lotteries were considered. The relationship between real pay-offs and risk aversion confirms the findings of Binswanger (1981), Miyata (2003) and Wik et al. (2004) that risk aversion increases as monetary pay-off increases. Cook et al. (2013) examined risk preferences in an urban setting in India using the experimental approach of Holt and Laury (2002) and observed a weak correlation between risk aversion and poverty.

In contrast to what Binswanger (1980, 1981), Miyata (2003), Wik et al. (2004) and Mosley and Verschoor (2005) concluded, Yesuf and Bluffstone (2009) using a data set obtained in Ethiopia found and concluded that there is a significant relationship between risk aversion and household characteristics such as income, wealth, marital status, gender and religion. In addition, considering a flexible number of parameters using regression analysis on coffee growers in Uganda, Hill and Robles (2011) also concluded that high-risk aversion causes less labour force to be allocated to risk crops, and this scenario is only for farmers who are not wealthier (endowment effect).

Dillenberger and Rozen (2015) explained how the primacy and reinforcement effect can influence risk attitude on lotteries (a typical decision-making under uncertainty). These authors used a history-dependent risk attitude (HDRA) model to explain how prior dissatisfactions and excitements endogenously influence decision-makers' ability to take risk. The HDRA model states that decision-maker's behaviour towards risk depends on history, and thus path dependency exists. The concept of history influencing risk attitude was also tested by Thaler and Johnson (1990). This study is aimed at testing the existence of path dependence and its determinants, arguing that individuals display choice stickiness.

Using either the expected utility theory (EUT) and the prospects theory (PT), Thaler and Johnson (1990) found that prior gains cause less risk aversion behaviour whilst prior losses enable individuals to be risk averse as subjects will try minimising future losses, unless the outcome of taking the risk allows the decision-maker to fully recover the amount previously lost. Barberis (2013) agreed with Thaler and Johnson (1990) that past experiences influence risk attitudes. Using stock market performance, Barberis, Min and Tano Santos (2001) concluded that investors are willing to take more risk after a positive outcome, thus resulting in increases in stock prices and less risk seeking after a decline in stock prices.

Weber and Zuchel (2003) differed with Thaler and Johnson (1990) and Barberis et al. (2001) as they found a weak evidence supporting this literature, noting that prior gains cause riskseeking behaviour and prior losses cause risk aversion (behaviour change). Based on Weber and Zuchel (2003), conclusions made by Thaler and Johnson (1990) and Barberis (2013) are only applicable if two stages betting games were displayed. In contrast, Weber and Zuchel (2003) noted that if it is a portfolio, risk taking is likely to occur after losses as compared to after gains. Using the Iowa Gambling Task (IGT), Franken, Irina and Muris (2006) also found greater risk taking after a loss than a gain (Schneider, Kauffman \& Ranieri 2016). Asymmetric reactions, however, not tested in this article are critical and therefore worth noting.

Furthermore, using Basketball players, Rao (2009) noted that players may attempt more complicated shoots after a chain of successful shots. Reinforcement of past experiences causes cognitive biases, and individuals might become risk averse after suffering a disappointment and less risk aversion after elation. In a gambling scenario, the existence of housing money effect was confirmed, where individuals were more enthusiastic to take risk after positive primacy reinforcement of a gain. Early outcomes of a gamble cause optimism and pessimism. However, in real life, small gains and losses happen and these early outcomes are more of reality than exception to create any bias. Positive outcome on early gamble causes optimism, and higher risk is taken using the housing money effect, which is the existence of losses until subjects break even. The existence of disappointments will make individuals less risk averse so as to recover what they have lost. The same may apply in livelihood activities, and if one has not been successful, they will be less risk averse (fearing to try new things), that is, being risk taking, given the past losses. This implies that the poor may easily be entrapped into poverty. This article is focused on investigating that so as to help understand why the poor remain in low-income categories and why inequality persists.

\section{Methodology}

To generate data, an experimental design was followed, using the approach developed by Yesuf and Bluffstone (2009). The design consists of two versions of path dependence elicitation tasks: gains only and gains and losses. Each version of the game has framed prospects, each with a $50 \%$ probability of being a good day and a $50 \%$ probability of being a bad day. Each subject is asked to choose one framed choice out of the five prospects available (Appendix 1) per round. After choosing one amongst the five available prospects per round (one at a time), a coin is tossed per round: if the outcome of the toss is head, then the subject receives the reward of a good day on that prospect; however, if the outcome of the toss is tail, the reward of a bad day is given. From Appendix 1, it can be seen that if the subject chooses prospect 5 of the first 
round, whether the subject gets head or tail, a return of R2.502 is given out - earnings for sure (certainty, zero risk). If the subject chooses any other prospect, for example, prospect 1 , a coin is tossed; if head, a good day return of R10 is given out, otherwise $\mathrm{R} 0$ is given out because it will be a bad day. The degree of risk aversion decreases (moving from certainty to more uncertain prospects) as subjects choose prospects towards the bottom option list (prospect 1).

The 1st, 2nd and 3rd rounds are done using real monetary pay-off where individuals are paid real money associated with the decision they have made and the outcome of the game (Wilk et al. 2004). The three rounds involve small to intermediate pay-offs which are equivalent to the net cash flow subjects obtain given a bad or a good day in their current economic activities. The 4th and 5th rounds are hypothetical lotteries that do not enable real payments of outcomes. Hypothetical pay-off is based on hypothetically framed questions concerning the risk and outcomes but without any pay-off being paid (Wilk et al. 2004). The study is also interested in comparing risk preferences across the two forms of pay-offs.

The experiment is summarised using the $\mathrm{z}$-measure developed by Abderrezak (1985). The z-measure is equal to the change in the expected value of the prospect divided by the change in standard deviation of the prospect (Abderrezak 1985). The subjects are informed about the five prospects, all having similar costs but different output levels depending on a $50 \%$ probability of good or bad outcome; for each alternative, the expected gain and range increase, as shown in the good and bad outcomes of each of the prospects.

Given this set-up, one is able to explicitly test for decreasing absolute risk aversion (DARA) and increasing partial risk aversion (IPRA)-type behaviours. Absolute risk aversion is investigated by presenting an identical choice set (e.g. Table 1) to households who have different levels of wealth. Wealth of each subject could not be determined $a$ priori; therefore, we controlled for wealth ex post using information generated from the survey (see Appendix 3) measuring access to different kinds of assets (around the key livelihood assets).

Langlois and Cosgel (1993); Sandmo (2010) defined risk aversion as a scenario where individuals prefer lower return with certainty than higher return with uncertainty. However, in the 1980s, two definitions emerged, with the first one established by Abderrezak (1985): non-expected utility theories are used to define risk aversion as the difference between certainty equivalence and the expected value under consideration. According to Segal and Spivak (1990), the second definition was proposed by Chew, Karni and Safra (1987), which asserts that risk aversion exists when preferences decrease as risk increases. Even though the definitions look different, when the von NeumannMorgenstern theorem is applied to the two definitions, it

2.Approximately $\$ 0.33$.
TABLE 1: Round 1: Illustration with upper and lower limits per prospect.

\begin{tabular}{lcccccl}
\hline Prospect & $\begin{array}{c}\text { Bad } \\
\text { day }\end{array}$ & $\begin{array}{c}\text { Good } \\
\text { day }\end{array}$ & $\begin{array}{c}\text { Expected } \\
\text { value (EV) }\end{array}$ & SD & CPRA coefficient & Risk classification \\
\hline 5 & 2.5 & 2.5 & 2.5 & 0 & $\infty$ to 0.741 & Extreme \\
4 & 2 & 5.5 & 3.75 & 1.75 & 0.741 to 0.50 & Severe \\
3 & 1.5 & 7.0 & 4.25 & 2.75 & 0.50 to 0.4 & Intermediate \\
2 & 1 & 8.5 & 4.675 & 3.875 & 0.4 to 0.33 & Moderate \\
1 & 0 & 10 & 5 & 5 & 0.33 to $-\infty$ & Neutral preferring \\
\hline
\end{tabular}

Source: Adapted for this study from Yesuf, M. \& Bluffstone, R.A., 2009, 'Poverty, risk aversion, and path dependence in low-income countries: Experimental evidence from Ethiopia', American Journal of Agricultural Economics 91(4), 1022-1037. https://doi.org/10.1111/j.1467-8276. 2009.01307.x

CPRA, constant partial risk aversion; SD, standard deviation

depicts a concave utility function in both. To test for IPRA responses, we then increased the outcomes (pay-offs) of the first-line choice set (prospect 5) by factors of 10, 12.5, 25 and 25 . These are prospects 5 , in rounds $2-5$.

We summarise our experimental results in risk aversion measures using a constant partial risk aversion (CPRA) utility function of the form $U=(1-\gamma) c^{(1-\gamma)}$, where $\gamma$ is the coefficient of risk aversion and $c$ is the certainty equivalent of a prospect. The basic structure of the experiment, using Round 1 as an example and including the upper and lower limits of the CPRA coefficients, is given in Table 1. We control for order and money effects by randomising the order of games within each category. It is imperative to note that path dependence is considered as being locked in a state by history (Arthur 1983) continuing to make the same choices despite the outcome (more especially negative outcomes).

After completing the gains-only experiment (rounds 1-5), tasks with the possibility of both gains and losses (see Appendix 2) are offered to each subject that qualifies and is willing to participate in that variant. Given the poverty of most participants and that we needed to observe the actions of subjects after performance in the first set of games, we did not force households to participate in the second part of the experiment. For a similar reason, it is necessary to conduct the gains-only games first and subjects accumulate earnings that will be used to cover loses in gains and losses game. Option to participate in gains and losses task is given to those who have earned at least R150 from the gains only and elect to participate (subjects had an option not to participate without any repercussions and this was made known to them from the beginning). Out of our conveniently recruited sample of 205 adults aged between 18 and 60 years, 196 subjects were eligible to play the 'gains and losses' task (had earned at least R150 from gains only task), but 10 subjects decided not to participate and these are treated as extremely risk averse, leaving 186 subjects.

To avoid the possibility of major financial losses, the two highest stakes task was performed hypothetically, and no actual gains or losses occurred. We acknowledge the possibility of self-selection in the gains and losses games and making rounds 4 and 5 hypothetical creates possible problems of bias. Given the nature of the study setting, however, there was no choice but to make these compromises in line with related literature (Yesuf \& Bluffstone 2009). 
This study also aimed at investigating the determinants of risk aversion. Given that our risk aversion measure is a continuous variable, ordinary least squares (OLS) was a viable estimation technique. However, OLS estimates are biased and inconsistent if unobserved heterogeneities are correlated with our right-side variables. Given the panel nature of our data (subject responding repeatedly to the variations in the games), consistent estimates can be obtained using either fixed or random effects models (Baltagi 2015). Such models also have the benefit of addressing endogeneity bias if endogeneity is mainly caused by time-varying (in our case, game varying) factors (Wooldridge 2010). Fixed effects address endogeneity even when time-invariant unobserved factors like household heterogeneity exist (Wooldridge 2010), but we are not able to use fixed effects because wealth, which is a key variable of interest, is household-specific and would automatically be dropped. In that regard, we use random effects and address potential endogeneity that results because of time-invariant factors by including as many householdspecific explanatory variables as possible.

\section{Description of the study site and household descriptive statistics}

Individuals were invited to a common venue for experiments through door knocking in the urban and peri-urban areas, pamphlets handed at street corners and word of mouth. The experiment subjects were drawn from Buffalo City Metropolitan Municipality in Eastern Cape province, which is one of the low-income provinces in South Africa with a GDP per capita of R3651 and a population of 848000 (ECSECC 2017). Social welfare is important for the survival of the low income in this province, as it is estimated that in 2018 there were about 17.8 million social grant recipients in South Africa of which approximately $15.32 \%$ (2.727 million people) were from the Eastern Cape (Kamer 2020). Poverty level in Buffalo City Municipality is very high amongst Africans, followed by mixed race people, Asians and white people in that order. ECSECC (2017) revealed that approximately 58.6\% of Africans who live in Buffalo City Municipality have low income, followed by mixed race people with $34.8 \%$, Asians with $6.4 \%$ and only $0.4 \%$ of white people are reported poor. This categorisation is based on Statistics South Africa upper bound poverty line definition, which was quoted at R1183 in 2018 (Statistics South Africa 2018). Over 450000 of 848000 people were living in poverty in 2018, which is below the upper bound poverty line of R1183. Of the economically active group, $26.3 \%$ are unemployed. Poverty is very much entrenched in South Africa, increasing in incidence and severity amongst the Africans. This motivated the present study to determine if the poor are trapped in that condition through path dependence.

\section{Ethical consideration}

Ethical approval to conduct the study was obtained from the University of Fort Hare Research Ethics Committee (clearance number: 270710-028-RA Level 1) on 05 March 2018.

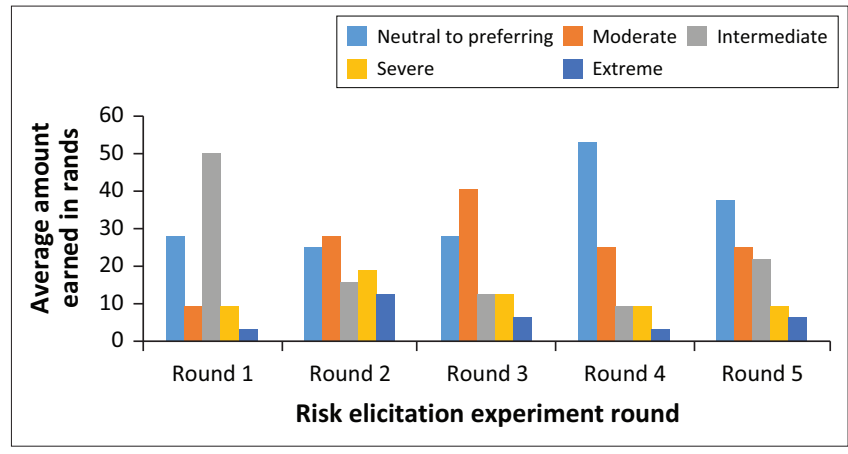

FIGURE 1: Gains only games - Distribution of risk appetite.

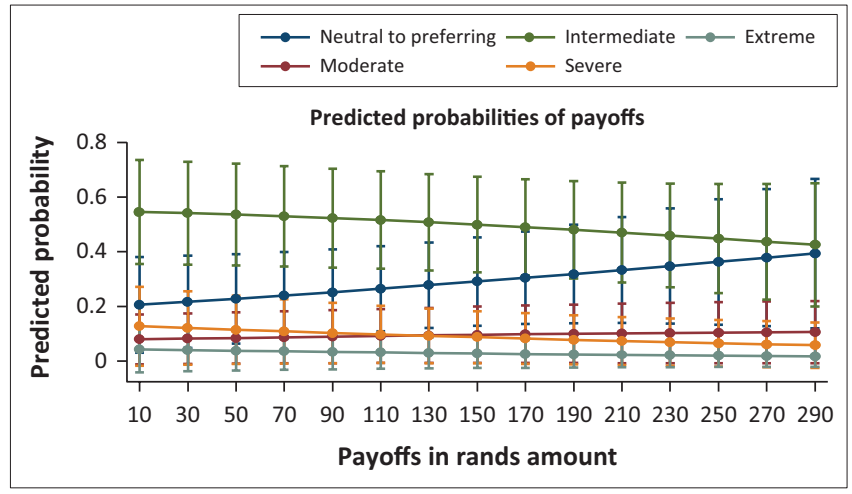

FIGURE 2: Gains and losses games - Distribution of risk appetite.

\section{Results presentation and discussion}

Figures 1 and 2 present frequencies of risk appetite per round, comparing the gains only task (Figure 1) and the gains and losses task (Figure 2). In the gains only, there is a variation of which of the appetite level is dominant across the rounds. In Round 1, risk neutrality dominates; rounds 2 and 3 have moderate-risk aversion, whilst rounds 4 and 5 have category neutral-to-preferring dominating. The latter was hypothetical and with larger amounts. It appears that subjects were willing to take a gamble (be less risk averse) when larger amounts were involved (equivalently, when pay-offs are hypothetical), compared to when the amounts are smaller (also case when real pay-offs are involved).

Subjects who played the second game/task of gains and losses are the ones who have won at least specific amount of money in part A and are also willing (self-selection), which poses bias to the study. Nonetheless, the parametric approaches applied later in the analysis catered for this. It appears that the gains and losses are significantly more neutral to risk preferring than risk averse (Figure 2). Risk aversion increases in rounds 4 and 5 - again hypothetical and large amounts involved. Subjects may have feared to lose substantial monies as large amounts were at stake.

Table 2 presents the chi-square $\left(\chi^{2}\right)$ results of testing association between the same level rounds on the two types of games. As shown in the table, a $\chi^{2}$ test that risk aversion is equivalent in both kinds of games (gains only vs. gains and losses) is rejected 
TABLE 2: Chi-square test of association.

\begin{tabular}{lcc}
\hline Hypothesis & $\chi^{2}$ statistics & $p$ \\
\hline Gain only in round 1 is equivalent to gains and losses in Round 1 & 13.883 & 0.062 \\
Gain only in round 2 is equivalent to gains and losses in Round 2 & 10.693 & 0.08 \\
Gain only in round 3 is equivalent to gains and losses in Round 3 & 15.424 & 0.040 \\
Gain only in round 4 is equivalent to gains and losses in Round 4 & 13.760 & 0.017 \\
Gain only in round 5 is equivalent to gains and losses in Round 5 & 18.183 & 0.091 \\
\hline
\end{tabular}

TABLE 3: Dependent variable is risk aversion coefficient (random effects results).

\begin{tabular}{lcc}
\hline Variable & Coefficient & Standard error \\
\hline Gender $(F=1)$ & -0.704 & 0.769 \\
Cash liquidity & $-0.046^{* * *}$ & 0.744 \\
Expected pay off & $0.7878^{* * *}$ & 0.335 \\
Family size & $-0.159^{* * *}$ & 0.082 \\
Dependency ratio & -0.515 & 0.443 \\
Age & $0.435^{* *}$ & 0.085 \\
Number of key assets held & $-0.697^{* *}$ & 0.239 \\
Gains_\&_Losses (=1) & $0.706^{*}$ & 0.676 \\
Literacy & 0.30245 & 0.353 \\
Previous success & $-0.341^{* *}$ & 0.240 \\
Hypothetical & -0.092 & 0.054 \\
\hline
\end{tabular}

Note: Levels of significance: *, $10 \% ; * *, 5 \% ; * * *, 1 \%$.

Wald $\chi^{2}=691.33 ;$ Adjusted $R$-Square $=0.48 ;$ Observations $=915$

for all portions of the experiment, implying that there is a statistically significant variation.

Having done the above preliminary test, this study conducted regression analysis to investigate the determinants of risk aversion. Given that our risk aversion measure (the CPRA coefficient) is a continuous variable, OLS is a viable estimation technique.

The results presented in Table 3 show that gender, dependency ratio and whether pay-off is hypothetical or not have no effect on risk aversion, implying that men and women are not different in terms of their risk appetite. However, cash liquidity reduces risk aversion, as the more liquid one becomes, the less is the demand for insurance as resources are available to cover any eventuality. This explains why the rich may keep on expanding their wealth, whilst the poor remain as poor. Mishi et al. (2020) in the case of Eastern Cape province, where this study is based, found that the rich can engage in high-value economic activities yet risky such as farming (farming has become riskier of late because of unreliable rainfall and more frequent and severe droughts) and the poor lack resources to engage or to insure potential losses if they dare to engage.

As the expected pay-off increases, the more risk averse the individual becomes, and individuals displayed appetite for bigger values regardless of the risk level. On the other hand, family size (proxy for competition for resources within household, and human capital quantity) reduces risk aversion, that is, it increases risk-taking. Also, the availability of more household members implies that some can be more risk-taking, and any loses are potentially covered by the earnings of other household members. Low-income families have limited resources and the members fight for the resources; this increases risk-taking. When one gets older, the more risk averse is the individual given the positive coefficient reflecting increase in risk aversion. This means that older subjects are worried about preserving and accumulating wealth as they face increasing possibility of zero earnings and entering a period of dissaving based on life cycle hypothesis.

Again, as the number of key assets held increases (assets such as household items, e.g. radio, cellphone, stove and sofas, amongst others), the less risk averse the individual becomes. These assets represent wealth; thus, the wealthier an individual is, the more risk-taking it is. Wealth acts as a cushion for losses, and individuals can aim for higher returns regardless of the inherent risk.

To test the IPRA hypothesis, we included the expected value of each game/task and expected the sign to be positive. On the other hand, to test for loss aversion, we included a dummy variable for games involving both gains and losses. Our hypothesis is that the estimated coefficient has a positive sign indicating that decision-makers treat opportunity losses differently from real losses. This hypothesis is confirmed, and we conclude that subjects are more afraid of actual loss (gains and losses games) than just gaining less than the maximum possible (opportunity loss in gains only). Households and individuals may not consider it loss, when they miss an opportunity; rather it is only a loss when their wealth accumulation is reduced (parting with what one has). When the economy presents opportunities, these can be easily missed, resulting in lower economic activities without the individuals feeling the pain about the loss.

To give insights regarding path dependence, we included a variable defined as $\sum X_{i}$, where $i$ is an index of the previous game played and $X$ takes a value of 1 if a respondent wins and -1 if he or she loses. The variable 'previous success' captures cognitive effects of past successes and failures that may affect the current period reactions to risk. We hypothesise that previous successes are negatively correlated with risk aversion in line with the study by Barberis (2013) and Schneider et al. (2016). On the other hand, a dummy variable for Round 5 examines the effect when games are hypothetical, and we hypothesise a negative sign. The results show a negative sign, although not statistically significant.

We expect wealthier households, who have enjoyed past economic successes and can better insulate themselves from shocks, to be less risk averse than low-income households. To test this hypothesis, we included possession of cash liquidity, key assets and past successes. All the three variables confirm the notion of wealthier, less risk averse. The low-income subjects maybe afraid to lose the little they have, with the richer ones having more opportunity to gamble and hopefully gain more. Mental accounting takes place, in which individuals can gamble with winnings but never with the principle - the 
endowment effect. A positive relationship between expected pay-off and the degree of risk aversion implies that people are less likely to take risks when highly expected gains and standard deviations are features of prospects. Wealth tends to reduce severe and extreme risk aversion. Subjects who win one more previous game or play hypothetical games are less likely to be extremely or severely risk averse. The results here imply that as one accumulates more wealth, he or she tends to be more risk preferring than risk averse. This is in line with the study by Weber and Zuchel (2003). Playing games involving losses increases the probability of being in the extreme risk aversion category.

Further illustration using predicted probabilities of pay-offs on risk preferences shows that as the pay-off increases, the probability of intermediate risk aversion decreases. Whilst on the other hand, neutral to prefering category probabilities increase as the pay-offs increase. The slopes of the moderate, extreme and severe categories are flatter compared to intermediate and risk neutral to prefering as pay-off increases; therefore, predictive probabilities of these three categories are not going to change as much as the risk neutral to prefering and intermediate category. This implies that the more risk averse an individual, the lower is the probability of changing his or her options - confirming the path dependence within risk aversion framework.

The variance inflaiton factor for each variable is below 5 , and so is the average. This implies that multicolinearity is not a problem in this model, and there are no ommitted variables. The estimations are, therefore, robust and inferences can be made from the results.

\section{Summary and conclusion}

This study set to investigate the presence of path dependency, and if found, the determinants of such behaviour in the case of South Africa. The study was carried out in the Eastern Cape province of South Africa, the second low-income region out of the nine provinces in the country. This study is of significance at two levels: first empirically, it advances the search of solutions to the triple challenges of employment, inequality and poverty, which is bedevilling South Africa at large and secondly, on the policy front by providing behavioural insights crucial to policy-making. For long, policies have failed to incorporate behavioural insights, at least in developing and emerging countries. The study helps to explain why the poor remain poor in the face of several government efforts to reduce poverty.

Using experimental designs with a mixture of real and hypothetical pay-offs, this study confirms the existence of path dependency amongst a predominantly low-income population. The results help provide an explanation to poverty trap and its entrenchment in South Africa, and by extension other social ills bedevilling South Africa and Eastern Cape province in particular. The study found that path dependency exists, and individuals are significantly risk averse, very much comfortable in making the same decision repeatedly, even if the outcome is not favourable. The behaviour is observed across gender and does not matter whether the outcome is real or imagined. It appears that individuals have a fear of the unknown, which reduces entrepreneurial activities and innovativeness within an economy. In this regard, creating opportunities for new business development and other activities to take place is necessary but not sufficient.

Making some progress in life (succeeding in one thing [in this study gaining in previous task]) boosts one's confidence and reduces risk aversion. The triple challenges can be addressed through paying attention to psychological factors, and how policy information is disseminated (framing) and what policies intend to target to change (behaviour of interest such as savings, entrepreneurship, education and cooperative projects, amongst other things) need to take behavioural aspects into account. Access to key livelihood, such as human capital (family size), finance (liquidity), and physical(suchas roadand telecommunications) and natural (land) infrastructures, is critical to reduce the extreme aversion, thereby allowing individuals to shift to new or alternative economic activities. Government at different levels needs to establish behavioural insights units to inform policy through better understanding of citizens and their decision-making.

The study can be improved by including subjects from highincome households and randomised order of tasks. In addition, causation can be tested using randomised control trials where resources permit.

\section{Acknowledgements}

The authors acknowledge the comments from participants at the African Finance Association Conference, 21-22 May 2019, Elephant Hills Resort, Victoria Falls, Zimbabwe.

\section{Competing interests}

The authors have declared that no competing interests exist.

\section{Authors' contributions}

All authors contributed equally to this work.

\section{Funding information}

Funding for this research was obtained from the National Research Foundation (NRF) under Syden Mishi Grant UID: 118828. Opinions expressed and conclusions arrived at in this study are those of the authors and are not necessarily to be attributed to the NRF.

\section{Data availability statement}

Data sharing is not applicable to this article as no new data were created or analysed in the study. 


\section{Disclaimer}

The views and opinions expressed in this article are those of the authors and do not necessarily reflect the official policy or position of any affiliated agency of the authors.

\section{References}

Achiba, G.A., 2018, 'Managing livelihood risks: Income diversification and the livelihood strategies of households in pastoral settlements in Isiolo County, Kenya', Pastoralism 8, 20. https://doi.org/10.1186/s13570-018-0120-x

Arthur, W.B., 1983, On competing technologies and historical small events: The dynamics of choice under increasing returns, IIASA, Laxenburg, Austria.

Baltagi, B.H., 2015, 'Solutions manual for econometrics', springer texts in business and economics, 3rd edn., Springer, Verlag Berlin Heidelberg, Germany.

Banerjee, A. \& Mullainathan, S., 2010, The shape of temptation: Implications for the economic lives of the poor, NBER Working Papers 15973, National Bureau of Economic Research, Inc.

Banerjee, S. \& Ewing, R., 2004, 'Risk, wellbeing and public policy', Economic Roundup, The Treasury, Australian Government 1(2), 21-44.

Barberis, N., Huang, M. \& Santos, T., 2001, 'Prospect Theory and Asset Prices', The Quarterly Journal of Economics 116(1), 1-53. https://doi.org/10.1162/ 003355301556310

Barberis, N.C., 2013, 'Thirty Years of Prospect Theory in Economics: A Review and Assessment', Journal of Economic Perspectives 27(1), 173-96. https://doi. org/10.1257/jep.27.1.173

Belaid, A., 1985, 'Farmers' risk attitudes in the eastern high plateau region of Algeria: An application of the experimental approach', viewed n.d., from https://ir.library. oregonstate.edu/concern/graduate thesis_or_dissertations/q237hv970

Binswanger, H.P., 1980, 'Attitudes Toward Risk: Experimental Measurement in Rural India', American Journal of Agricultural Economics 62(3), 395-407. https://doi. org/10.2307/1240194

Binswanger, H.P., 1981, 'Attitudes toward risk: Theoretical implications of an experiment in Rural India', The Economic Journal 91(364), 867. https://doi. org/10.2307/2232497

Chew, S.H., Karni, E. \& Safra, Z., 1987, 'Risk aversion in the theory of expected utility with rank dependent probabilities', Journal of Economic Theory 42, 370-381.

Concina, L., 2014, Risk attitude \& economics, Number 2014-01 of Les Regards, Foundation for an industrial safety culture, Toulouse, viewed 23 March 2019, from http://www.foncsi.org/

Cook, J., Chatterjee, S., Sur, D. \& Whittington, D., 2013, 'Measuring risk aversion among the urban low income in Kolkata, India', Applied Economics Letters 20(1) 1-9. https://doi.org/10.1080/13504851.2011.644235

David, P.A., 1985, 'Clio and the economics of QWERTY', The American Economic Review 75(2), 332-337.

David, A., Guilbert, N., Hamaguchi, N., Higashi, Y., Hino, H., Leibbrandt, M. et al., 2018, Spatial poverty and inequality in South Africa: A municipality level analysis, viewed 23 March 2019, from http://www.opensaldru.uct.ac.za/ handle/11090/902\%0A http://www.opensaldru.uct.ac.za/bitstream/ handle/11090/902/2018_221_Saldruwp.pdf?sequence=1.

Dillenberger, D. \& Rozen, K., 2015, 'History-dependent risk attitude', Journal of Economic Theory 157(1763), 445-477. https://doi.org/10.1016/j.jet.2015.01.020

Dobusch, L. \& Schübler, E., 2013, 'Theorizing path dependence: A review of positive feedback mechanisms in prominent cases', Industrial and Corporate Change 22(3), 617-647. https://doi.org/10.1093/icc/dts029

Eather, J. \& Frawley, N., 2015, 'Economic overview', National Treasury (South Africa) 5(2), 6-25. https://doi.org/10.1177/0027950108089668

ECSECC, 2017, Buffalo City Metro Municipality socio economic review and outlook, p. 107 viewed 17 August 2018, from http://www.ecsecc.org/documentrepository/ informationcentre/buffalo-city-metro-municipality_44557.pdf.

Franken, I.H.A., Irina, G. \& Muris, P., 2006, 'The rich get richer and the low income get low incomeer: On risk aversion in behavioral decision-making', Judgment and Decision Making 1, 153-158.

Golik, J., 2016, 'Expected utility hypothesis - Its origin and development', Unpublished Masters Dissertation, Gdansk University of Technology, viewed n.d., from https:// doi.org/10.13140/RG.2.2.13642.57288

Harrison, G.W., 2019, 'The behavioral welfare economics of insurance', The Geneva Risk and Insurance Review 44, 137. https://doi.org/10.1057/s10713-019-00042-y

Harrison, G.W., Lau, M.I. \& Rutström, E.E., 2007, 'Estimating risk attitudes in Denmark: A field experiment', Scandinavian Journal of Economics 109(2), 341-368. https:// doi.org/10.1111/j.1467-9442.2007.00496.x

Hill, R. \& Robles, M., 2011, WP flexible insurance for heterogeneous farmers: Results from a small scale pilot in Ethiopia, Discussion Paper, International Food Policy Research Institute (IFPRI), Washington, DC (1092), pp. 1-34. https://doi. org/10.1111/j.1464-410X.2008.08158.x

Holt, C.A. \& Laury, S.K., 2002, 'Risk aversion and incentive effects', American Economic Review 92(5), 1644-1655. https://doi.org/10.1257/000282802762024700

Knight, F.H., 1921, Risk, uncertainty and profit, Hart, Schaffner and Marx, New York, NY.
Langlois, R.N., 1993, 'Transaction-Cost Economics in Real Time', Industrial and Corporate Change, June 1992, 99-127.

Langlois, R.N. \& Cosgel, M.M., 1993, 'Frank knight on risk, uncertainty, and the firm: A new interpretation', Economic Inquiry 31(3), 456-465. https://doi.org/10.1111/ j.1465-7295.1993.tb01305.x

List, J. \& Shogren, J., 1998, 'The deadweight loss of Christmas: Comment', American Economic Review 88(5), 1350-1356.

Mabilo, M., 2018, Women in the informal economy: Precarious labour in South Africa, Unpublished master's dissertation, Stellenbosch University, Stellenbosch, South Africa

Mani, A., Mullainathan, S., Shafir, E. \& Zhao, J., 2013, 'Poverty impedes cognitive function', Science 341(6149), 976-980. https://doi.org/10.1126/science.1238041

Meyer, D.J. \& Meyer, J., 2005, 'Relative risk aversion: What do we know?' Journal of Risk and Uncertainty 31, 243-262. https://doi.org/10.1007/s11166-005-5102-x

Mishi, S., Sikhunyana, Z., Ngonyama, N. \& Sibanda, K., 2020, 'Livelihood strategies and diversification amongst the poor: Evidence from South African household surveys', The Journal for Transdisciplinary Research in Southern Africa 16(1), a726. https://doi.org/10.4102/ td.v16i1.726

Miyata, S., 2003, 'Household's risk attitudes in Indonesian villages', Applied Economics 35(5), 573-583. https://doi.org/10.1080/0003684022000020823

Mosala, S.J., Venter, J.C.M. \& Bain, E.G., 2017, 'South Africa's economic transformation since 1994: What influence has the National Democratic Revolution (NDR) had?', The Review of Black Political Economy 44, 327. https://doi.org/10.1007/s12114017-9260-2

Mosley, P. \& Verschoor, A., 2005, 'Risk attitudes and the "vicious circle of poverty", European Journal of Development Research 17(1), 59-88. https://doi.org/ 10.1080/09578810500066548

Ndabeni, L.L. \& Maharajh, R., 2013, The Informal Sector and the Challenges of Development in South Africa, viewed 11 October 2018, from http://wwwieri.org. $\mathrm{za} / \mathrm{sites} /$ default/files/outputs/informal_sector_and_the_challenges_of_ development in south africa.pdf

O'Donoghue, T., 2015, 'Teaching a behavioral economics elective: Highlighting the science of economics', The American Economic Review 105(5), 391-395. https:// doi.org/10.1257/aer.p20151048

Pillay, U., 2008, 'Urban policy in post-apartheid South Africa: Context, evolution and future directions', Urban Forum 19(2), 109-132. https://doi.org/10.1007/s12132 008-9038-5

Rao, J., 2009, Experts' perceptions of autocorrelation: The hot hand fallacy among professional basketball players, Working Paper series, pp. 1-25, viewed 09 April 2019, from http://www.justinmrao.com/playersbeliefs.pdf.

Rogan, M. \& Skinner, C., 2017, 'The nature of the South African informal sector as reflected in the quarterly labour-force the nature of the South African informal sector as reflected in the quarterly labour-force survey', February, 1-33, viewed 22 March 2019, from http://www.redi3x3.org/sites/default/files/Rogan \%26 Skinner 2017 REDI3×3 Working Paper 28 Informal sector in SA - QLFS analysis.pdf.

Rosen-Schwarz, G. \& Shapira, Z., 2018, 'Prospect theory and strategic decisionmaking', in M. Augier \& D.J. Teece (eds.), The Palgrave encyclopedia of strategic management, pp. 21-28, Palgrave Macmillan, London.

Sandmo, A., 2010, 'Uncertainty in the Theory of Public Finance', Geneva Risk Insur Rev 35, 1-18. https://doi.org/10.1057/grir.2010.1

Sarlo, C.A., 2013, Poverty: Where Do We Draw the Line? Fraser Institute, Canada viewed 02 September 2019, from https://www.fraserinstitute.org/sites/default/ files/Poverty-where-do-we-draw-the-line.pdf.

Schneider, S.L., Kauffman, S. \& Ranieri, A., 2016, 'The effects of spositive and negative experiences on risk taking', Judgment and Decision Making 11(5), 424.

Segal, U. \& Spivak, A., 1990, 'First order versus second order risk aversion', Journal of Economic Theory 51(1), 111-125. https://doi.org/10.1016/0022-0531(90)90053-M

Sharyn, S., Roshan, G. \& Duncan, M., 2018, 'Women's experiences of informal street trading and well-being in Cape', South African Journal of Occupational Therapy 48(1), 28-33. https://doi.org/10.17159/2310-3833/2017/vol48n1a6

Simatele, M.C., Mishi, S., Tsegaye, A., Makhetha-Kosi, P., Kapingura, F. \& Khumalo, S.A., 2016, Harnessing livelihood strategies for pro-low income policy intervention in Eastern Cape South Africa- Addressing the poverty and inequality challenge; Grant project report to European Union and The Presidency, South Africa, viewed 09 June 2018, from http://psppdknowledgerepository.org/ component/jidownloads/send/23-grantee-research/609-enhancing-pro-low income-growth-through-livelihood-strategies-in-the-eastern-capeincome-growth-through-liveliti
province?option=com jdownloads

Statistics South Africa, 2018, Statistics South Africa 2 P0310.1, National Poverty Lines (2018), Pretoria, South Africa, pp. 1-10.

Sydow, J., Schreyögg, G. \& Koch, J., 2009, 'Organizational path dependence: Opening the black box', Academy of Management Review 34(4), 689-709. https://doi. org/10.5465/amr.34.4.zok689

Thaler, R.H. \& Johnson, E.J., 1990, 'Gambling with the house money and trying to break even: The effects of prior outcomes on risky choice', Management Science 36(6), 643-660. https://doi.org/10.1287/mnsc.36.6.643

Thomas, P.J., 2016, 'Measuring risk-aversion: The challenge', Measurement 79 285-301. https://doi.org/10.1016/j.measurement.2015.07.056

Tsurui-Sato, K., Kumano, N., Honma, A., Matsuyama, T., Haraguchi, D., Teruya, K. et al., 2018, 'Why evictions do not deter street traders: Case study in Accra, Ghana', Applied Entomology and Zoology 53(1), 107-115. https://doi.org/10.1007/s13355 017-0535-7 
Weber, M. \& Zuchel, H., 2003, 'How do prior outcomes affect risk attitude?', viewed 09 June 2018, from http://citeseerx.ist.psu.edu/viewdoc/download?doi=10.1.1.194. 7655\&rep=rep1\&type=pdf

Webster, M., 2008, 'Incorporating path dependency into decision-analytic methods: An application to global climate-change policy', Decision Analysis 5(2), 60-75. https://doi.org/10.1287/deca.1080.0114

Wik, M., Kebede, T.A., Bergland, O. \& Holden, S.T., 2004, 'On the measurement of risk aversion from experimental data', Applied Economics 36(21), 2443-2451. https:// doi.org/10.1080/0003684042000280580

Wilkinson, N. \& Klaes, M., 2012, An introduction to behavioral economics, 2nd edn., Palgrave Macmillan, Basingstoke, United Kingdom.
Wooldridge, J.M., 2010, Econometric analysis of cross section and panel data, 2nd edn., The MIT Press, Massachusetts Institute of Technology, Cambridge, Massachusetts, United States of America.

World Bank Group, 2015, World development report 2015: Mind, society, and behavior, World Bank, Washington, DC, viewed 06 June 2019, from https://openknowledge.worldbank.org/handle/10986/20597 License: CC BY 3.0 IGO.

Yesuf, M. \& Bluffstone, R.A., 2009, 'Poverty, risk aversion, and path dependence in low-income countries: Experimental evidence from Ethiopia', American Journal of Agricultural Economics 91(4), 1022-1037. https://doi.org/10.1111/j.1467-8276. 2009.01307.x 
Appendix 1: Gains Only framework - Rounds 1-5 $\& 5$ prospects per each round

TABLE 1-A1: (Gains only) lottery games used in the experiment (amounts in rands). GAINS PROSPECT FIRST ROUND R2.S (REAL)

\begin{tabular}{|c|c|c|c|}
\hline & & & \\
\hline & BAD DAY & GOOD DAY & CHOICE \\
\hline 5 & 2.5 & 2.5 & \\
\hline 4 & 2 & 4.5 & \\
\hline 3 & 1.5 & 6.5 & \\
\hline 2 & 1 & 8 & \\
\hline 1 & 0 & 10 & \\
\hline \multirow[t]{2}{*}{ GAINS CHOICE } & \multicolumn{3}{|c|}{ SECOND ROUND RI2.5 (REAL) } \\
\hline & BAD D AY & GOOD DAY & CHOICE \\
\hline 5 & 12.5 & 12.5 & \\
\hline 4 & 10 & 22.5 & \\
\hline 3 & 7.5 & 30 & \\
\hline 2 & 5 & 37.5 & \\
\hline 1 & 0 & 50 & \\
\hline \multirow[t]{2}{*}{ GAINS PROSPECT } & \multicolumn{3}{|c|}{ THIRD ROUND R25 (REAL) } \\
\hline & BAD DAY & GOOD DAY & CHOICE \\
\hline 5 & 25 & 25 & \\
\hline 4 & 20 & 45 & \\
\hline 3 & 15 & 65 & \\
\hline 2 & 7.5 & 85 & \\
\hline 1 & 0 & 100 & \\
\hline \multirow[t]{2}{*}{ GAINS PROSPECT } & \multicolumn{3}{|c|}{ FOURTH ROUND R50 (HYPOTHETICAL) } \\
\hline & BAD DAY & GOOD DAY & CHOICE \\
\hline 5 & 50 & 50 & \\
\hline 4 & 40 & 90 & \\
\hline 3 & 30 & 135 & \\
\hline 2 & 15 & 175 & \\
\hline 1 & 0 & 200 & \\
\hline \multirow[t]{2}{*}{ GAINS PROSPECT } & \multicolumn{3}{|c|}{ FIFTH ROUND R75 (HYPOTHETICAL) } \\
\hline & BAD DAY & GOOD DAY & CHOICE \\
\hline 5 & 75 & 75 & \\
\hline 4 & 65 & 135 & \\
\hline 3 & 45 & 200 & \\
\hline 2 & 25 & 250 & \\
\hline 1 & 0 & 300 & \\
\hline
\end{tabular}

Appendix 2: Gains \& Losses framework - Rounds 1-5 \& 5 prospects per each round

TABLE 1-A2: (Gains and losses) lottery games used in the experiment (amounts in rands).

\begin{tabular}{|c|c|c|c|}
\hline \multicolumn{4}{|c|}{ First round R5 (real) } \\
\hline \multicolumn{4}{|c|}{ Gains and losses } \\
\hline Prospect & Bad day & Good day & Choice \\
\hline 5 & 0 & 0 & \\
\hline 4 & -0.5 & 3 & \\
\hline 3 & -1 & 4.5 & \\
\hline 2 & -1.5 & 6 & \\
\hline 1 & -2.5 & 7.5 & \\
\hline \multicolumn{4}{|c|}{ Second round R25 (real) } \\
\hline \multicolumn{4}{|c|}{ Gains and losses } \\
\hline Prospect & Bad day & Good day & Choice \\
\hline 5 & 0 & 0 & \\
\hline 4 & -2.5 & 10 & \\
\hline 3 & -5 & 17.5 & \\
\hline 2 & -7.5 & 25 & \\
\hline 1 & -12.5 & 37.5 & \\
\hline \multicolumn{4}{|c|}{ Third round R50 (real) } \\
\hline \multicolumn{4}{|c|}{ Gains and losses } \\
\hline Prospect & Bad day & Good day & Choice \\
\hline 5 & 0 & 0 & \\
\hline 4 & -5 & 20 & \\
\hline 3 & -10 & 40 & \\
\hline 2 & -17.5 & 60 & \\
\hline 1 & -25 & 75 & \\
\hline \multicolumn{4}{|c|}{ Fourth round R100 (hypothetical) } \\
\hline \multicolumn{4}{|c|}{ Gains and losses } \\
\hline Prospect & Bad day & Good day & Choices \\
\hline 5 & 0 & 0 & \\
\hline 4 & -10 & 40 & \\
\hline 3 & -20 & 85 & \\
\hline 2 & -35 & 125 & \\
\hline 1 & -50 & 150 & \\
\hline \multicolumn{4}{|c|}{ Fifth round R150 (hypothetical) } \\
\hline \multicolumn{4}{|c|}{ Gains and losses } \\
\hline Prospect & Bad day & Good day & Choices \\
\hline 5 & 0 & 0 & \\
\hline 4 & -10 & 10 & \\
\hline 3 & -30 & 75 & \\
\hline 2 & -50 & 175 & \\
\hline 1 & -75 & 225 & \\
\hline
\end{tabular}




\section{Appendix 3: Research questionnaire Demographics}

1. Please circle your sex:

MALE FEMALE

2. What is your age (in years) :

3. Mother tongue:

4. Race
a. Black African
b. Mixed race
c. Indian/Asian
d. White
e. Other

5. Household's main source of income:
a. Salaries/wages
b. Social grants
c. Pension
d. Remittances
e. Business income
f. Farming/agricultural activities
g. Other (specify)

6. What is the highest level of education you have?
a. No formal education
b. Below matriculation
c. Matriculation
d. University education
e. Postgraduate studies

7. What is the highest level of education of the head of the household?
a. No formal education
b. Below matriculation
c. Matriculation
d. University education
e. Postgraduate studies

8. What is your household total monthly income?
a. Less than $\mathrm{R} 500$
b. Between R500 and R1000
c. Between R1000 and R3000
d. Between R3000 and R5000
e. More than R5000

9. What is your current marital status?
a. Single
b. Married/cohabitant
c. Separated
d. Divorced
e. Widowed

10. Number of household members:

11. How do you consider yourself: are you a person who, in general, takes risks or do you prefer to avoid them? Please grade your willingness to take risks by marking a number between 0 and 10 below, where ' 0 ' represents 'zero willingness to take risks' and ' 10 ' represents 'total willingness to take risks'.

$\begin{array}{lllllllllll}1 & 2 & 3 & 4 & 5 & 6 & 7 & 8 & 9 & 10 & 11\end{array}$

12. In the past 3 months, how often have you or your family not had food to eat?
a. Never
b. Rarely (less than one meal per month, on average)
c. Sometimes (about one meal per week, on average)
d. Often (more than one meal per week, on average)

e. Very often (about or more than one meal per day, on average)

f. I do not know

g. I prefer not to answer

13. In the past 3 months, how often have you or your family gone without a cash income?

a. Never

b. Rarely (just a few days over the past 3 months)

c. Sometimes (a few days per month not counting normal rest days)

d. Often (a few days for most weeks not counting normal rest days)

e. Very often (a few days almost every week not counting normal rest days)

f. I do not know

g. I prefer not to answer

14. I would like to ask you how much you trust people from various groups. Could you tell me for each whether you trust people from this group: (C) completely, (S) somewhat, (NM) not very much or (NA) not at all? You may also answer DK for 'I don't know' or NPA for 'I prefer not to answer'.

a. People in this room (excluding the study staff, just the individuals participating like you)

b. Your family

c. Your neighbourhood

d. People in your village

e. People you meet for the first time

f. People of another religion

g. People of another nationality

15. You loan money to someone who does not repay, or you and your neighbour are in a dispute over land or goods, would you seek help from any of the following? Please indicate $Y$ for 'yes', $\mathrm{N}$ for 'no', DK for 'I don't know' and PFA for 'I prefer not to answer' on each row.
a. The police
b. Your relatives
c. Your close friends
d. Village leader
e. Religious leader

16. Generally speaking, would you say that most people can be trusted or that you need to be very careful in dealing with people? Choose only one answer below.

a. Most people can be trusted

b. Need to be very careful

17. Do you have a bank account? YES/ NO

18. How many people in your household have a bank account?

19. Did your household borrow money last week or last month?

If not, circle 'No' and skip Yes / No

20. Did your household lend out money last week or last month? If not, circle 'No' and skip Yes / No

21. Did your household save any money last week?

If not, circle 'No' and skip Yes / No
a. In what form did you save?
i. In the home
ii. Bank account 
iii. Savings club

iv. Family member

v. Safe keeping with friend/neighbour

vi. Other:

b. I do not know

c. I prefer not to answer

22. Did your household save any money last month?

If not, circle 'No' and skip

$$
\text { Yes / No }
$$

a. In what form did you save?

i. Bank account

ii. Savings club

iii. Family member

iv. Safe keeping with friend

v. Safe keeping with neighbour

vi. Other:

b. I do not know

c. I prefer not to answer

23. What is the total value of your household savings? Rand a. I do not know

b. I prefer not to answer

24. What is the total value of loans your household has given out? Rand

a. I do not know

b. I prefer not to answer

25. Do you plan to repay any loans next week and/or next month? If not, circle 'No' and skip

Yes / No

a. How much money do you plan to repay next week? Rand

b. How much money do you plan to repay next month (not

including the the amount listed under 24a?

Rand

26. What is your occupation?
a. Not employed
b. Informally employed
c. Formally employed
d. Self employed
e. Student

27. Tell me your understanding of the causes of poverty ....... 